\title{
ПОНЯТИЕ И СОДЕРЖАНИЕ ПУБЛИЧНОГО МЕРОПРИЯТИЯ В АДМИНИСТРАТИВНОМ ПРАВЕ
}

$$
\Pi^{\circ}
$$

убличное мероприятие - это открытая, мирная, доступная каждому, проводимая в форме собрания, митинга, демонстрации, шествия или пикетирования либо в различных сочетаниях этих фоорм акция, осуществляемая по инициативе граждан РФ, политических партий, других общественных объединений и религиозных объединений, в том числе с использованием транспортных средств. Целью публичного мероприятия является свободное выражение и формирование мнений, а также выдвижение требований по различным вопросам политической, экономической, социальной и культурной жизни страны и вопросам внешней политики;
Публичные мероприятия в России представляют собой сложные и очень значимые социальные явления. Тем не менее, мы обращаем ваше внимание на то, что все еще отсутствуют общепризнанное определение понятия «публичные мероприятия» и единая классификация ${ }^{1}$ таковых, поскольку они далеко не однородны².

${ }^{1}$ См.: Коптев Н.В. Административно-правовая охрана порядка организации и проведения публичных мероприятий: дис. ... канд. юрид. наук. - М., 2001. - С. 35.

2 См.: Звягин М.М., Костенников М.В., Куракин А.В. Административно-правовая охрана общественного порядка при проведении публичных мероприятий в Российской Федерации. - Домодедово, 2008. - С. 88. 
Надо сказать, что определения понятий «собрание», «митинг», «демонстрация», «шествие» и «пикетирование», данные в Законе РФ «О собраниях, митингах, демонстрациях, шествиях и пикетированиях» от 19 июня 2004 г., практически не расходятся с определениями понятий ученыхисследователей, например:

- собрание - это совместное присутствие граждан в специально отведенном или приспособленном для этого месте для коллективного обсуждения каких-либо общественно значимых вопросов.

Д.В. Шутько, Л.Л. Попов дают следующее понятие собранию: совместное присутствие граждан в заранее определенном месте, в заранее определенное время для коллективного обсуждения и решения каких-либо вопросов;

- митинг - массовое присутствие граждан в определенном месте для публичного выражения общественного мнения по поводу актуальных проблем преимущественно общественно-политического характера.

Характеризуя публичные мероприятия, В.Ф. Дерюжинский говорит о том, что «митинги являются, прежде всего, выразителями нужд и интересов народа, который посредством их заявляет о том, что в данное время его тяготит, беспокоит или волнует» ${ }^{3}$.

По мнению Д.В. Шутько митинг - это фрорма организованного выражения общественного мнения, массовой поддержки резолюций, требований и других обращений граждан, проводимая в заранее определенном месте ${ }^{4}$.

А Л.А. Нудненко в своей статье отмечает, что митинг - массовое собрание граждан для публичного выражения отношения к решениям и действиям лиц и организаций, событиям общественно-политической жизни путем массовой поддержки резолюции

- демонстрация - организованное публичное выражение общественных настроений группой граждан с использованием во время передвижения плакатов, транспарантов и иных средств наглядной агитации.

\footnotetext{
3 См.: Дерюжинский В.Ф. Полицейское право. - СПб., 1908.С. 64.

4 См.: Комментарий к Конституции Российской Федерации / под ред. Б.Н. Топорнина, Ю.М. Батурина, Р.Г. Орехова. - М., 1994. - С. 189.

${ }_{5}^{5}$ См.: Нудненко Л.А. Теоретические основы права граждан РФ на проведение собраний, митингов, шествий и пикетирования // Журнал российского права. - 2000. - № 12. - С. 64.
}

Д.В. Шутько говорит отом, чтодемонстрацияфрорма организованного выражения не только коллективного, но и индивидуального мнения по любому вопросу общественной и государственной жизни, а Л.А. Нудненко считает, что демонстрация - публичное выражение группой людей общественно-политических настроений с использованием во время шествия плакатов, транспарантов и иных наглядных средств;

- шествие - массовое прохождение граждан по заранее определенному маршруту в целях привлечения внимания к каким-либо проблемам. Ю.И. Скуратов и В.В. Гущин придерживаются мнения, что шествия отличаются от толпы организованностью, следовательно, уличное шествие - это «движение по определенному маршруту, который заранее сообщается органу охраны порядка» ${ }^{6}$;

- пикетирование - фрорма публичного выражения мнений, осуществляемого без передвижения и использования звукоусиливающих технических средств путем размещения у пикетируемого объекта одного или более граждан, использующих плакаты, транспаранты и иные средства наглядной агитации. Л.Л. Попов дает лаконичную формулировку исследуемого понятия: пикетирование - наглядная демонстрация группой граждан своих настроений и взглядов без шествия и звукоусиления ${ }^{7}$. Л.А. Нудненко, исследуя природу публичных мероприятий, также отмечает, что пикетирование - это наглядная демонстрация гражданином или группой граждан своих настроений и взглядов без шествия и звукоусиления. Пикетирование может осуществляться посредством демонстрации лозунгов, плакатов, иных предметов, иллюстрирующих идеи и взгляды ${ }^{8}$.

Известно, что понятие и термин (терминологическое словосочетание) «публичное мероприятие» произошли от слов «массовое действо» - т.е. публичное массовое зрелище, в котором участвуют большие массы народа (исполнители и зрители).

\footnotetext{
${ }^{6}$ См.: Скуратов Ю.И. Свобода собраний, митингов и демонстраций // Советское государство и право. - 1989. - № 7. - С. 35.

${ }^{7}$ Комментарий к Кодексу РСФСР об административных правонарушениях / под ред. И.И. Веремеенко, Н.Г. Салищевой, М.С. Студеникиной. - М., 2001. - С. 568-572.

${ }^{8}$ См.: Нудненко Л.А. Указ соч. - С. 65.

9 См.: Кравцов В.М. Административно-правовая охрана общественного порядка при проведении собраний, митингов,
} 


\section{Полицейская деятельность $2 \cdot 2013$}

К данному понятию близко примыкает понятие «манифестация» - обнаружение, проявление, изъявление чего-либо, например, патриотических чувств; публично-массовые выступления, шествия ${ }^{10}$.

После событий октября 1917 г. возникли новые формы народного празднества, которые приобрели новое качество: публичные театрализованные шествия, представления на улицах и площадях и т.п.

Они проходили во многих городах и собирали под открытым небом десятки тысяч участников и зрителей. Не случайно эти мероприятия вызывали огромный интерес не только в нашей стране, но и за рубежом. В этой связи представляется необходимым определить, что именно понимается под понятием публичного мероприятия в науке ${ }^{11}$.

Как отмечает В.В. Ларин, публичное мероприятие - это организованное действие (совокупность действий или явлений социальной жизни) с участием больших масс людей, совершающееся в интересах трудящихся с целью удовлетворения их политических, духовных, фризических и других потребностей, являющееся формой реализации их прав и свобод, а также формой социального общения между людьми и способом выработки единства установок личности, коллектива, общества в целом ${ }^{12}$.

На наш взгляд, В.В. Ларин верно определил границы этого социального явления, позволяющие отличить его от других явлений, предложив основные признаки публичного мероприятия: наличие больших масс людей; организованность действия (действий); наличие цели (целей). Нам представляется, к данным признакам следует также присоединить такой признак как публичность.

В.Ф. Дерюжинский отмечал, что публичное собрание - собрание, доступное неопределенному числу лиц, или хотя бы определенному числу лиц,

уличных шествий и демонстраций: дис. ... канд. юрид. наук. M., 1991. - C. 38.

${ }^{10}$ См.: Советский энциклопедический словарь. - М., 1989. C. 768 .

${ }^{11}$ См.: Звягин М.М., Костенников М.В., Куракин А.В. Административно-правовая охрана общественного порядка при проведении публичных мероприятий в Российской Федерации. - Домодедово, 2008. - С. 88.

12 См.: Ларин В.В. Понятие административно-правовой охраны общественного порядка при проведении массовых мероприятий // Теория и практика совершенствования охраны общественного порядка. - М., 1985. - С. 54. но лично не заинтересованных устроителем собрания. Собрания же, в которых участвуют одни члены законно существующего общества или союза, и посторонние лица не присутствуют, он относит к публичным ${ }^{13}$.

Следовательно, опираясь на вышеизложенное, считаем необходимым обратить внимание на то, что массовое мероприятие будет всегда являться публичным.

Н.В. Караханов публичное мероприятие определяет как организованную, санкционированную или несанкционированную форму активных действий больших масс людей (групп), которые нацелены на выражение воли, защиту своих прав и свобод, законных интересов, на удовлетворение потребностей в экономической, политической, социально-культурной и других материальных и духовных сфрерах ${ }^{14}$.

Д.К. Нечевин говорит о том, что публичное мероприятие представляет собой организованную форму активных действий большого числа граждан, осуществляемых в общественных местах, в целях выражения коллективного мнения по различным вопросам общественной жизни, духовного и эмоционального удовлетворения ${ }^{15}$.

В приведенных определениях внимание акцентировано на организационно-правовых аспектах публичных мероприятий. Данные определения содержат прямое указание на обязательную организацию или санкционирование проведения активных действий компетентными государственными органами или общественными организациями. А.М. Алоян и В.И. Эглит ${ }^{16}$ указывают и на то обстоятельство, что в некоторых случаях целенаправленные и правомерные действия больших групп людей осуществляются на основании обычаев - в первую очередь это религиозные праздники, в которых в силу различных причин принимают участие и лица, далекие от религии. Однако и здесь также не в полной мере выявлены

\footnotetext{
13 См.: Дерюжинский В.Ф. Указ. соч. - С. 102.

${ }_{14}$ См.: Караханов Н.В. Управление горрайорганами внутренних дел при проведении массовых мероприятий. - М., 1992. - С. 6.

15 См.: Нечевин Д.К. Организация деятельности органов внутренних дел по обеспечению правопорядка при проведении массовых мероприятий // Предупреждение преступности и обеспечение безопасности в городах. - М., 2001. - С. 90.

${ }^{16}$ См.: Алоян А.М., Эглит В.И. Правовое регулирование охраны общественного порядка при проведении 15 массовых мероприятий // Административно-правовые проблемы охраны общественного порядка. - М., 1987.
} 
сущность и содержание этого сложного и многоаспектного социального явления.

Н.В. Коптев отмечает, что публичное мероприятие - это организованная санкционированная или несанкционированная форма активных публичных действий больших масс (групп) людей в общественных местах в целях выражения их воли, защиты своих прав, свобод, законных интересов удовлетворения потребностей в экономической, политической социально-культурной других материальных и духовных сорерах ${ }^{17}$.

Данное определение содержит отмеченные выше основные признаки публичного мероприятия, но главное здесь заключается в том, что действия масс или групп преломляются, прежде всего, через категорию публичности, социальной активности, под которой понимается деятельное отношение людей к жизни общества, в котором они выступают как субъекты и носители социально значимых норм, идеалов, интересов и других человеческих ценностей.

В зависимости от характера собраний публичные мероприятия подразделяются на толпу - случайное собрание, сходку - нелегальное собрание, собственно собрание - если оно устроено легально лицами, живущими в определенной местности, и съезд или конференцию если собрание устраивалось лицами, живущими в разных местностях ${ }^{18}$.

Д.К. Нечевин классифицирует публичные мероприятия по следующим критериям:

а) по значимости: международные, общегосударственные, региональные и местные;

б) по месту проведения: мероприятия, проводимые в зданиях, сооружениях, спортивных комплексах, на открытой местности;

в) по периодичности проведения: разовые, повторяющиеся, повседневные;

г) по возможности участия: общедоступные, с ограничением числа участников;

д) по составу участников: массовые мероприятия могут быть дифференцированы на мероприятия со смешанным составом участников, либо представлены участниками, имеющими особый социальный статус;

е) по содержанию: общественно-политические; культурно-зрелищные; спортивно-массовые; религиозные (похоронные);

\footnotetext{
17 См.: Коптев Н.В. Указ. соч. - С. 28.

18 См.: Евтихиев А.Ф. Основы советского административного права. - Харьков, 1925. - С. 219.
}

ж) по масштабу: международные, общефедеральные, региональные и муниципального значения ${ }^{19}$.

Публичные мероприятия могут быть классифрицированы в зависимости от организационноправовой формы.

В зависимости от вида публичного мероприятия арсенал административно-правовых средств охраны общественного порядка при их проведении различен. Кроме того, как отмечает И.С. Полянская, «любое публичное мероприятие, независимо от целей должно быть мирным, то есть не носить насильственного или подстрекательского характера» $^{20}$.

В.В. Ивановский в начале $\mathrm{XX}$ в. говорил о том, что если открытие собрания допущено, то оно должно быть закрыто полицейским чиновником в следующих случаях:

1) когда собрание отклоняется от предмета его занятий;

2) когда в собрании высказываются суждения, возбуждающие вражду одной части населения против другой;

3) когда в собрании производятся неразрешенные денежные сборы;

4) когда в нем окажутся лица, в собрание не допускаемые, как лица вооруженные, военные нижние чины, а если собрание политическое, то и все лица военного звания, учащиеся низших и средних учебных заведений;

5) когда будет нарушен порядок собрания мятежными возглавиями, либо заявлениями, восхваляющими или оправдывающими преступление, заявлениями, возбуждающими призывы к насилию или неповиновению к властям, или заявлениями, угрожающими общественному спокойствию и безопасности ${ }^{21}$.

Классификации публичных мероприятий имеет важное практическое для органов внутренних дел в сорере организации охраны общественного порядка при проведении собраний митингов, демонстраций, шествий и пикетирования. Как от-

\footnotetext{
19 См.: Деятельность нарядов милиции по охране общественного порядка и безопасности в обычных и особых условиях. - М., 1996. - С. 3.

20 Полянская И.С. Конституционно-правовое регулирование права граждан Российской Федерации на проведение собраний, митингов и демонстраций, шествий и пикетирования: автореф. дис. ... канд. юрид. наук. - М., 2005. - С. 17.

${ }^{21}$ См.: Ивановский В.В. Учебник административного права. Полицейское право. Право внутреннего управления. - Казань, 1911. - С. 195.
} 
мечает Д.К. Нечевин, «классификация массовых мероприятий по сходным признакам дает общее представление об их широком спектре, что, в свою очередь, предполагает и многообразие правовых норм, регламентирующих их организацию и проведение 22 .

Понятно, что участие граждан в различных публичных мероприятиях - одна из форм реализации их прав и свобод, закрепленная в Конституции РФ. В процессе участия в таких мероприятиях граждане имеют возможность проявить личную и групповую инициативу, выразить от- ношение к тому или иному политическому, социальному или другому событию, явлению, потребовать от компетентных органов решения тех или иных вопросов ${ }^{23}$.

Дальнейшее развитие форм участия граждан в публичных мероприятиях в условиях демократии требует более детального изучения и уточнения понятийно-терминологического аспекта проблемы публичных мероприятий, что позволит совершенствовать правовые акты, регулирующие общественные отношения во время подготовки и проведения этих мероприятий.

\section{Библиографический список:}

1. Алоян А.М., Эглит В.И. Правовое регулирование охраны общественного порядка при проведении 15 массовых мероприятий // Административно-правовые проблемы охраны общественного порядка. - М., 1987.

2. Балтага Д.А. Политические свободы собраний, митингов, уличных шествий и демонстраций и их реализация в деятельности органов внутренних дел: дис. ... канд. юрид. наук. - М., 1993.

3. Голованев И.В. Правовые основы и организация охраны общественного порядка при проведении собраний, митингов, уличных шествий и демонстраций: автореф. дис. ... канд. юрид. наук. — М., 1992.

4. Дерюжинский В.Ф. Полицейское право. - СПб., 1908.

5. Деятельность нарядов милиции по охране общественного порядка и безопасности в обычных и особых условиях. - М., 1996.

6. Евтихиев А.Ф. Основы советского административного права. - Харьков, 1925.

7. Звягин М.М., Костенников М.В., Куракин А.В. Административно-правовая охрана общественного порядка при проведении публичных мероприятий в Российской Федерации. - Домодедово, 2008.

8. Ивановский В.В. Учебник административного права. Полицейское право. Право внутреннего управления. - Казань, 1911.

9. Кравцов В.М. Административно-правовая охрана общественного порядка при проведении собраний, митингов, уличных шествий и демонстраций: дис. ... канд. юрид. наук. — М., 1991.

10. Комментарий к Конституции РФ / под ред. Б.Н. Топорнина, Ю.М. Батурина, Р.Г. Орехова. - М., 1994.

11. Караханов Н.В. Управление горрайорганами внутренних дел при проведении массовых мероприятий. - М., 1992.

12. Коптев Н.В. Административно-правовая охрана порядка организации и проведения публичных мероприятий: дис. ... канд. юрид. наук. - М., 2001.

13. Ларин В.В. Понятие административно-правовой охраны общественного порядка при проведении массовых мероприятий // Теория и практика совершенствования охраны общественного порядка. М., 1985.

14. Нудненко Л.А. Теоретические основы права граждан РФ на проведение собраний, митингов, шествий и пикетирования // Журнал российского права. - 2000. — № 12.

15. Нечевин Д.К. Организация деятельности органов внутренних дел по обеспечению правопорядка при проведении массовых мероприятий // Предупреждение преступности и обеспечение безопасности в городах. - М., 2001.

\footnotetext{
22 См.: Организация деятельности органов внутренних дел по обеспечению правопорядка при проведении массовых мероприятий // Предупреждение преступности и обеспечение безопасности в городах. - М., 2001. - С. 92.
}

${ }^{23}$ См.: Голованев И.В. Правовые основы и организация охраны общественного порядка при проведении собраний, митингов, уличных шествий и демонстраций: автореф. дис. ... канд. юрид. наук. - М., 1992. - С. 13; Балтага Д.А. Политические свободы собраний, митингов, уличных шествий и демонстраций и их реализация в деятельности органов внутренних дел: дис. ... канд. юрид. наук. - М., 1993. - С. 19 и др. 
16. Полянская И.С. Конституционно-правовое регулирование права граждан Российской Федерации на проведение собраний, митингов и демонстраций, шествий и пикетирования: автореф. дис. ... канд. юрид. наук. - М., 2005.

17. Скуратов Ю.И. Свобода собраний, митингов и демонстраций // Советское государство и право. 1989. — № 7.

\section{References (transliteration):}

1. Aloyan A.M., Eglit V.I. Pravovoe regulirovanie okhrany obshchestvennogo poryadka pri provedenii 15 massovykh meropriyatiy // Administrativno-pravovye problemy okhrany obshchestvennogo poryadka. M., 1987.

2. Baltaga D.A. Politicheskie svobody sobraniy, mitingov, ulichnykh shestviy i demonstratsiy i ikh realizatsiya v deyatel'nosti organov vnutrennikh del: Dis. ... kand. yurid. nauk. - M., 1993.

3. Golovanev I.V. Pravovye osnovy i organizatsiya okhrany obshchestvennogo poryadka pri provedenii sobraniy, mitingov, ulichnykh shestviy i demonstratsiy: Avtoref. dis. ... kand. yurid. nauk. — M., 1992.

4. Deryuzhinskiy V.F. Politseyskoe pravo. - SPb., 1908.

5. Deyatel'nost' naryadov militsii po okhrane obshchestvennogo poryadka i bezopasnosti v obychnykh i osobykh usloviyakh. - M., 1996.

6. Evtikhiev A.F. Osnovy sovetskogo administrativnogo prava. - Khar'kov, 1925.

7. Zvyagin M.M., Kostennikov M.V., Kurakin A.V. Administrativno-pravovaya okhrana obshchestvennogo poryadka pri provedenii publichnykh meropriyatiy v Rossiyskoy Federatsii. — Domodedovo, 2008.

8. Ivanovskiy V.V. Uchebnik administrativnogo prava. Politseyskoe pravo. Pravo vnutrennego upravleniya. Kazan', 1911.

9. Kravtsov V.M. Administrativno-pravovaya okhrana obshchestvennogo poryadka pri provedenii sobraniy, mitingov, ulichnykh shestviy i demonstratsiy: Dis. ... kand. yurid. nauk. — M., 1991.

10. Kommentariy k Konstitutsii Rossiyskoy Federatsii / Pod red. B.N. Topornina, Yu.M. Baturina, R.G. Orekhova. - M., 1994.

11. Karakhanov N.V. Upravlenie gorrayorganami vnutrennikh del pri provedenii massovykh meropriyatiy. M., 1992.

12. Koptev N.V. Administrativno-pravovaya okhrana poryadka organizatsii i provedeniya publichnykh meropriyatiy: Dis. ... kand. yurid. nauk. - M., 2001.

13. Larin V.V. Ponyatie administrativno-pravovoy okhrany obshchestvennogo poryadka pri provedenii massovykh meropriyatiy // Teoriya i praktika sovershenstvovaniya okhrany obshchestvennogo po $r$ ryadka. M., 1985.

14. Nudnenko L.A. Teoreticheskie osnovy prava grazhdan RF na provedenie sobraniy, mitingov, shestviy $i$ piketirovaniya // Zhurnal rossiyskogo prava. - 2000. — № 12.

15. Nechevin D.K. Organizatsiya deyatel'nosti organov vnutrennikh del po obespecheniyu pravoporyadka pri provedenii massovykh meropriyatiy // Preduprezhdenie prestupnosti i obespechenie bezopasnosti $v$ gorodakh. - M., 2001.

16. Polyanskaya I.S. Konstitutsionno-pravovoe regulirovanie prava grazhdan Rossiyskoy Federatsii na provedenie sobraniy, mitingov i demonstratsiy, shestviy i piketirovaniya: Avtoref. dis. ... kand. yurid. nauk. - M., 2005.

17. Skuratov Yu.I. Svoboda sobraniy, mitingov i demonstratsiy // Sovetskoe gosudarstvo i pravo. — 1989. — № 7. 